\title{
Learning curve in 20 years of brace treatment
}

\author{
Franz Landauer \\ From 11th International Conference on Conservative Management of Spinal Deformities - SOSORT 2014 \\ Annual Meeting \\ Wiesbaden, Germany. 8-10 May 2014
}

\section{Background}

The author has more than 20 years of experience in the treatment of scoliosis

\section{Aim}

Objectification of his own learning curve in brace treatment.

\section{Design}

Retrospective case study.

\section{Methods}

I compared a group of 100 outpatients treated 20 years ago with a further group of 100 outpatients treated recently. The brace indication depends on the SOSORTcriteria. Cobb angle was measured before treatment, primary correction and follow up $>1$ years after weaning of the brace. Compliance was estimated by our own compliance score [1]. All braces are made by one orthotist.

\section{Results}

First examination

At the initial presentation Cobb angle changed from $31^{\circ}$ (range $20^{\circ}-56^{\circ}$ ) to $27^{\circ}$ (range $20^{\circ}-46^{\circ}$ ) in cases Risser <II. The number of pretreated patient without any orthopedic examination rise up to $8 \%$ and nearby $10 \%$ did not accept bracing. Also the number of non idiopathic scoliosis rise with the availability of MRI up to $6 \%$.

\section{Bracing}

Primary correction progressed in the group of $20^{\circ}-30^{\circ}$ (58\% to $72 \%$ ), $30^{\circ}-40^{\circ}$ ( $47 \%$ to $\left.56 \%\right)$ and $40^{\circ}-50^{\circ}$ (32\% to $41 \%)$.

20 years ago I ordered 23 hours as fulltime bracing, but now 20 hours per day is the maximum, but the differentiation between good (73\%) and bad compliance (27\%) did not change significantly.

\section{Follow up}

The final results at follow up have improved in the last 20 years from $28^{\circ}$ to $23^{\circ}$, but the spread is still large. The number of progression $>50^{\circ}$ decreased from $12 \%$ to $5 \%$.

\section{Summary}

Now scoliosis is diagnosed earlier, but the number of unskilled pretreatment and rejection of treatment increased. Our experience lowers the number of idiopathic scoliosis. We have learned to make bracing more effective in primary correction and at follow up despite of a lower wearing time per day. We could not influence compliance significantly.

\section{Conclusion}

Patients increasingly influence therapeutic regime. Part time bracing becomes the main option in outpatient treatment. There is still potential to improve brace-management. In outpatient treatment "compliance of the staff" seems to be a problem. An experienced orthopedic technician leads to a good standard, but it lacks on comparison and competition.

\section{Published: 4 December 2014}

\section{Reference}

1. Landauer F, Wimmer C, Behensky H: Estimating the final outcome of brace treatment for idiopathic thoracic scoliosis at 6-month follow-up. Pediatr Rehabil 2003, 6(3-4):201-207.

doi:10.1186/1748-7161-9-S1-O25

Cite this article as: Landauer: Learning curve in 20 years of brace treatment. Scoliosis 2014 9(Suppl 1):O25. 